\title{
Termination and Distribution Modalities of the Small Saphenous Vein and its Implications in the Surgery of Chronic Venous Insufficiency
}

\author{
Gaye $\mathrm{M}^{1,2 *}$, P A Dieng ${ }^{2}$, Diagne $\mathrm{PA}^{2}$, Ndiaye $\mathrm{Ai}^{1}$, Wade $\mathrm{R}^{1}$, Diagne $\mathrm{AM}^{3}$, Nazarian $\mathrm{S}^{4}$, A Ndiaye ${ }^{2,5}$
}

\author{
${ }^{1}$ Laboratory of Anatomy and Organogenesis, Faculty of Medicine, Pharmacy and Dentistry, University of Cheikh Anta Diop, Dakar (Senegal) \\ ${ }^{2}$ Department of Thoracic and Cardiovascular Surgery, Fann Hospital, Dakar (Senegal) \\ ${ }^{3}$ Department of Orthopedics and Traumatology, Pikine Hospital, Dakar (Senegal) \\ ${ }^{4}$ Laboratory of Anatomy, Faculty of Medicine, University of Marseille (France) \\ ${ }^{5}$ Laboratory of Anatomy and Organogenesis, Training and research Unit of Medical science, University of Assane Seck, Ziguinchor (Senegal)
}

DOI: 1 10.36348/sijap.2020.v03i03.002 $\quad$ | Received: 19.03 .2020 | Accepted: 27.03 .2020 | Published: 30.03 .2020

*Corresponding author: Magaye GAYE, MD

\section{Abstract}

The small saphenous vein (SSV) has several termination modalities and several types of afferent branches. The latter participate in the physiopathology of insufficiency of the small saphenous vein and explain the majority of recurrences after open or endovenous surgical cures. This study details the modes of termination and topography of afferents of the SSV. This is a cadaveric dissection involving 62 members of fresh and embalmed anatomical subjects. A popliteal approach and an extension is made towards the femoral region and towards the lateral malleolus are performed. Several parameters have been studied: the number of SSV, the number and distribution of terminal branches in the popliteal vein, in the great saphenous vein or in the thigh and the existence of musculocutaneous afferents of leg and thigh. We found that $45 \%$ of terminations were with a sapheno-popliteal junction. This form was absent in $55 \%$ of the cases. Consequently, the termination was either in the great saphenous vein, or in the posterior muscular compartment of the thigh, or in integumentary branches of the leg or thigh, or in the twin veins. This SSV received, in its course, twin veins, femoral veins, and integumentary veins.These anatomical variations of termination make a rigorous clinical and ultrasonographic examination indispensable in order to have a good mapping of the vein an to avoid recurrence of varicoses after surgery.

Keywords: Variations, termination, small saphenous vein, sapheno-popliteal junction.

Copyright @ 2020: This is an open-access article distributed under the terms of the Creative Commons Attribution license which permits unrestricted use, distribution, and reproduction in any medium for non-commercial use (NonCommercial, or CC-BY-NC) provided the original author and source are credited.

\section{INTRODUCTION}

The small saphenous vein (SSV) presents several anatomical variations of termination $[1,2]$. This vein is often the seat of varicose veins whose treatment can be medical, open surgical or endovenous. The realization of these techniques requires a perfect knowledge of the anatomy of the small saphenous vein, especially at the level of its termination where the lack of knowledge of the different possibilities can be a source of recurrence after surgical treatment of varicose veins [3]. In addition to the surgical traps they perform, these variations, must also be taken into account by the sonographer for preoperative mapping of the small saphenous vein and its branches $[4,5]$. Variations like the absence of sapheno-popliteal junction are frequent.

Through this work of dissection, we will expose the variations of termination of the small saphenous vein and will give the recurrence mechanisms and the various tricks to avoid the surgical traps, during the management of the venous insufficiency of the small saphenous vein.

\section{MATERIALS AND METHODS}

To perform this work, we dissected 62 pelvic limbs, 32 on the right side and 30 on the left side on 34 fresh and embalmed adult anatomical subjects, on January 2017 to July 2018. There were 23 men and 11 women aged 71 to 101 years. The dissection involved the 2 pelvic members in 28 subjects and one pelvic limb in 6 subjects. The inclusion criterias are adult subjets without macroscopic lesions or deformation. Members with macroscopic lesions were excluded from the study. This study was carried out concomitantly at the services of Pathological Anatomy of the Hospital Aristide Le Dantec, the General Hospital of Grand-Yoff and the Anatomy Laboratory of the Faculty of Medicine of Marseille. 
The material used was a current dissection box, a tape measure, a millimetric compass (Verneuil), a metal pin, a camera, an image processing software (Adobe Photoshop).

In the supine patient, to identify the small saphenous vein, we made two transverse incisions across the hand on both sides of the popliteal fold, then a median incision connecting the two incisions allowing the separation of the two skin flaps as an open book. After spotting the vein, we continued down the median incision to the calcaneal insertion of the calcaneal tendon and then extended it on the outer edge of the foot for $5 \mathrm{~cm}$. The incision was prolonged at the posterior of the thigh and, if necessary, up to the level of the buttock or at the level of the femoral trine when we had found an ascending branch, in order to see its involvement in the great saphenous vein or at the level of the muscles of the thigh or buttocks.

We noticed:

- The number of small saphenous veins,
- The number and the distribution of terminal branches in the popliteal vein, in the great saphenous vein or in the thigh

- The existence of musculocutaneous afferent branches of the leg and thigh;

The protocol of this study approved by the ethics committee of the faculty of Medicine, Pharmacy and Dentistry of the University of Cheikh Anta Diop.

\section{RESULTS}

Number of small saphenous veins

We noted only one small saphenous vein in 60 cases. In 2 cases $(3.2 \%)$, the small saphenous vein was twofold (table I).

\section{Presence of sapheno-popliteal junction}

In 28 cases $\left(45 \%^{\circ} ; 16\right.$ times right and 12 times left of our dissections, the small saphenous vein ended in the popliteal vein producing an arch (Figure 1). In 3 of these cases, $4.83 \%$ of our dissections, the arch was double (Figure 2).

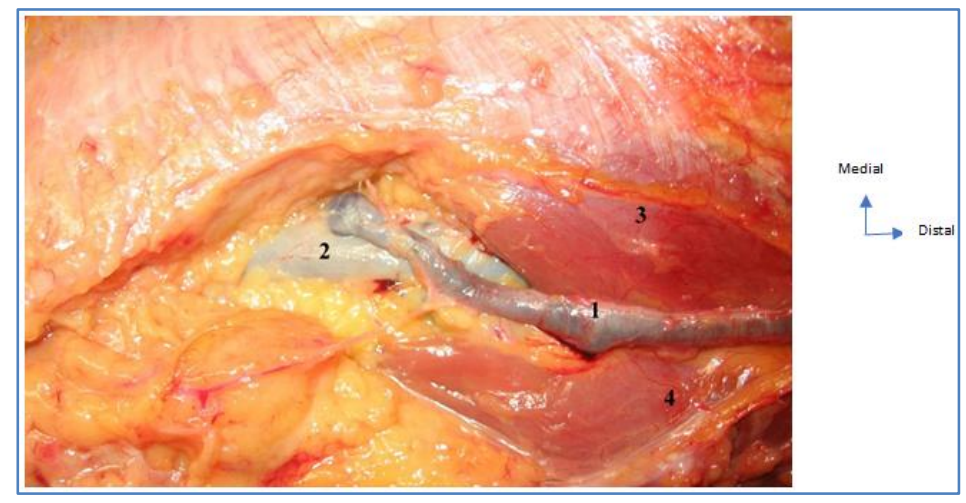

Fig-1: Left popliteal fossa, the small saphenous vein arch

1- small saphenous vein; 2- popliteal vein; 3-internal twin muscle; 4- external twin muscle

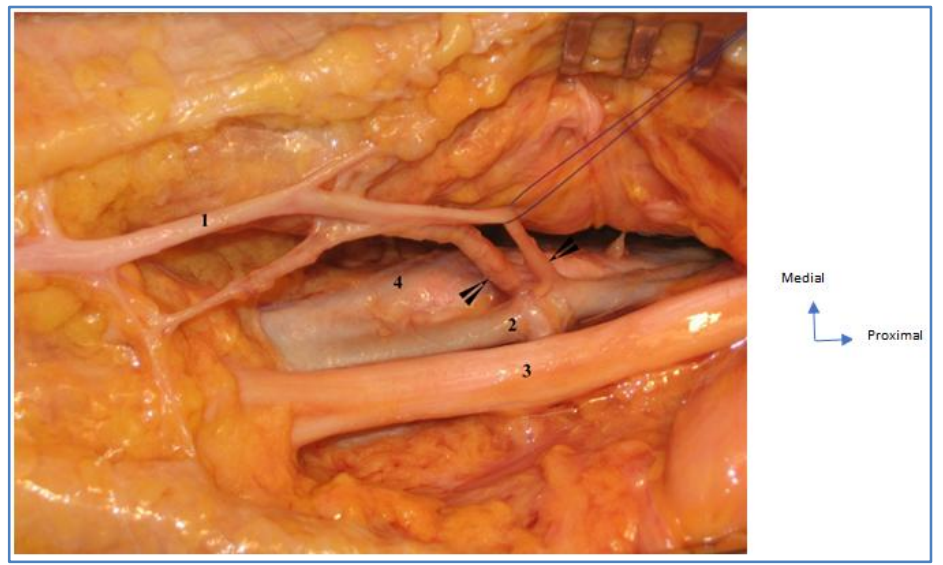

Fig-2: Right popliteal fossa, duplication of the small saphenous vein arch 1- small saphenous vein; 2- popliteal vein; 3- sciatic nerve; 4- popliteal artery

The sapheno-popliteal junction averaged 4.20 $+/-2.9 \mathrm{~cm}$ above the knee joint spacing and $4.22+/-1$ $\mathrm{cm}$ within the vertical line passing through the head of the fibula (Figures 3 and 4).
The arch was the exclusive termination in 6 cases $(9.67 \%)$ and in 11 cases $(17.75 \%)$, the arch received small muscular and integumentary afferents veins of the leg and thigh with a predominance of twin veins (Figures 5 and 6). 
Ten times (16.12\%), the SSV ended with an arch in the popliteal vein that receives a superficial vein from the posterior compartment of the thigh. The latter was subfascial (8 cases) or subcutaneous ( 2 cases) (Figure 7). There were also twin, hamstring and cutaneous branches.
In one case, the SSV was divided into two branches, one of which fell into the popliteal vein and the other into the great saphenous vein (GSV).

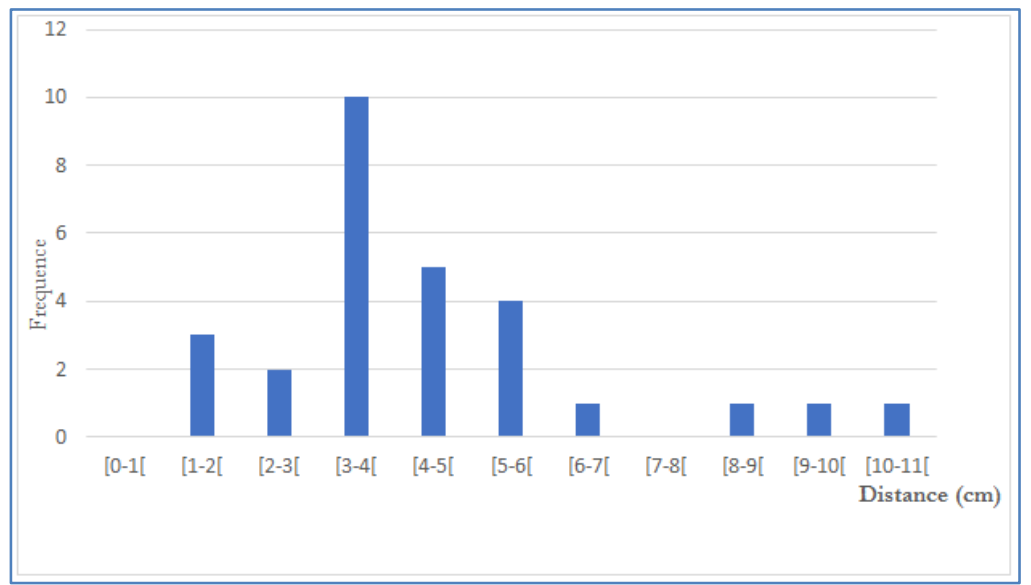

Fig-3: Distance from the saphenopopliteal junction to the joint space

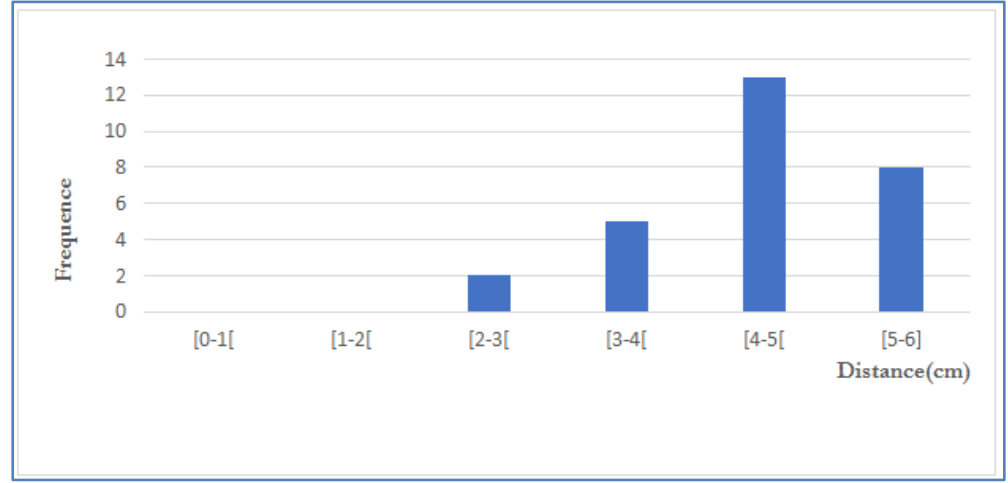

Fig-4: Distance from the saphenopopliteal junction to the fibula head

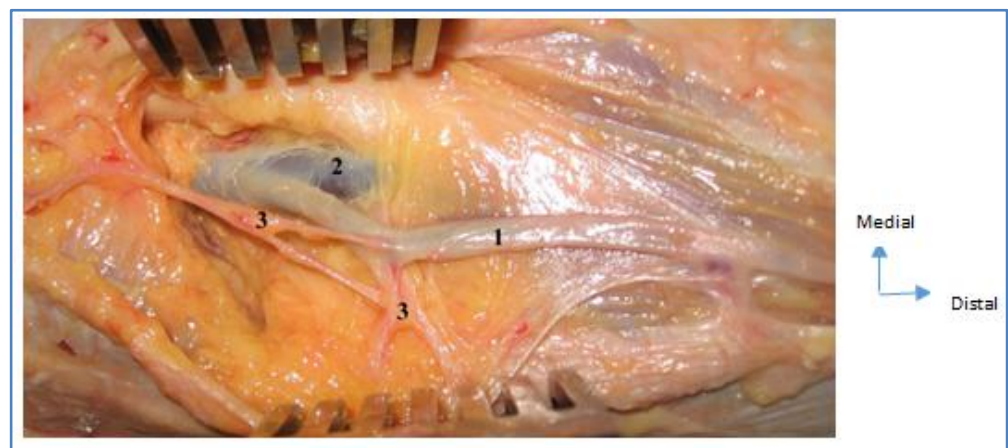

Fig-5: Left popliteal fossa, the small saphenous vein arch

1- small saphenous vein; 2- popliteal vein; 3- fascio-cutaneous afferent branche 


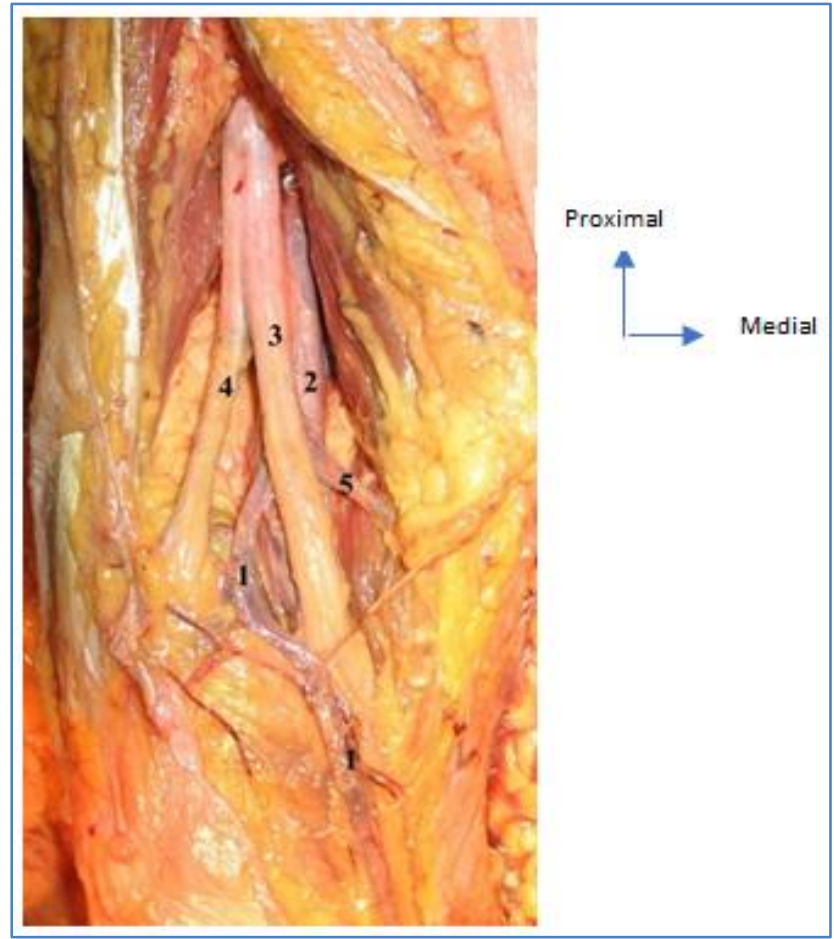

Fig-6: Left popliteal fossa, small saphenous vein and internal twin vein common arch

1- small saphenous vein; 2- popliteal vein; 3- tibial nerve; 4- peroneal nerve; 5- internal twin vein

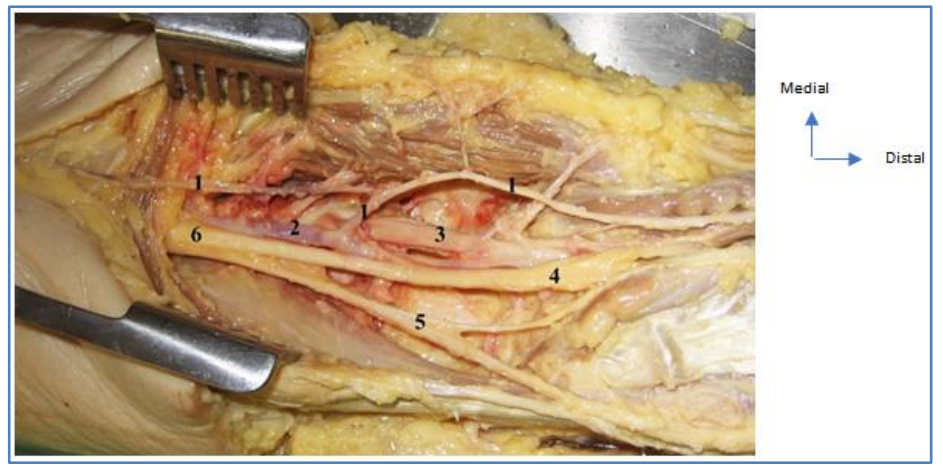

Fig-7: Left popliteal fossa, termination of the small saphenous vein in buttocks and posterior extension of the thigh

1- small saphenous vein; 2- popliteal vein; 3- popliteal artery; 4- tibial nerve; 5- peroneal nerve; 6- sciatic nerve

\section{Absence of sapheno-popliteal junction}

In the remaining 34 cases, there was no arch at the termination of the SSV. Which constituted $55 \%$ of our dissections.

The SSV ended in the upper femoral part of the GSV in 9 cases $(9.67 \%$ ) after having circumvented the medial side of the pelvic limb. This termination in the GSV was exclusive in 6 cases (Figures 8 and 9). In 3 cases, the SSV was divided into 2 branches that joined one the GSV and the other in the posterior muscular lodge of the thigh. This termination also received twin and femoral afferent branches in 4 cases.

In 16 cases $(25.80 \%)$, SSV was prolonged in the posterior muscular compartment of the thigh. This femoral termination was isolated and perforating in 8 cases (Figure 10). In 8 other cases, the femoral extension received collaterals arising from the twin and hamstring muscles, rarely from the teguments (Figure 11).

Six times $(9.67 \%)$, the SSV ended with a fascio-cutaneous posterior femoral extension, either exclusively ( 2 cases) or by receiving tegumentary branches of the leg and thigh (4 cases) or rarely muscular afferents veins.

Twice the SSV ended by giving twin branches and once, giving branches to the posterior muscles of the thigh (table I). 


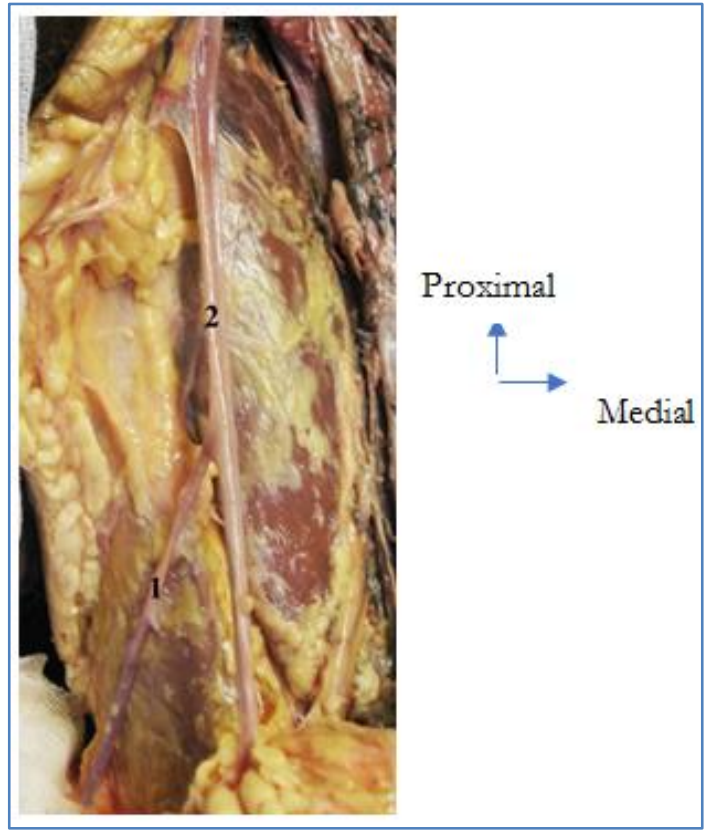

Fig-8: Right femoral region, termination of the small saphenous vein in the great saphenous vein 1- small saphenous vein; 2- great saphenous vein

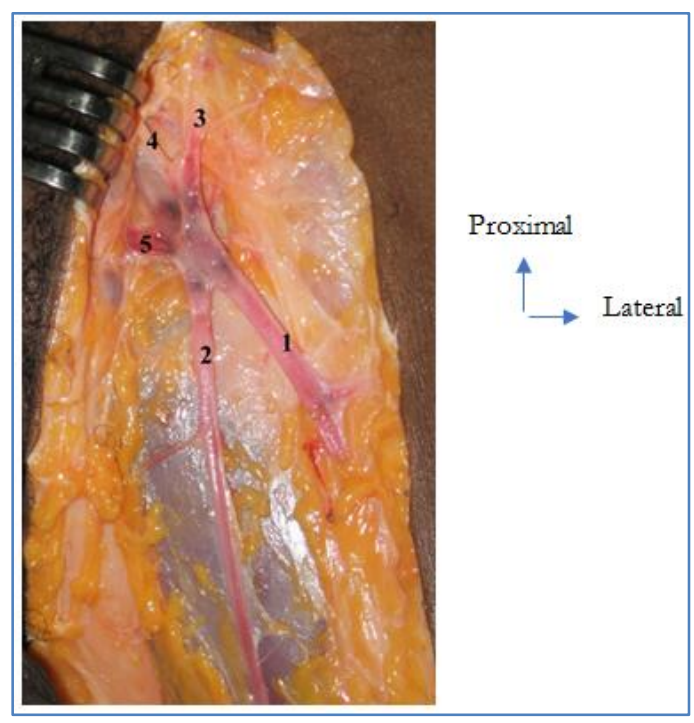

Fig-9: Left femoral trigon, termination of the small saphenous vein in the great Saphenous vein 1- small saphenous vein; 2- great saphenous vein; 3- circumflex iliac superficial vein; 4- superficial epigastric vein; 5- external pudendal veins

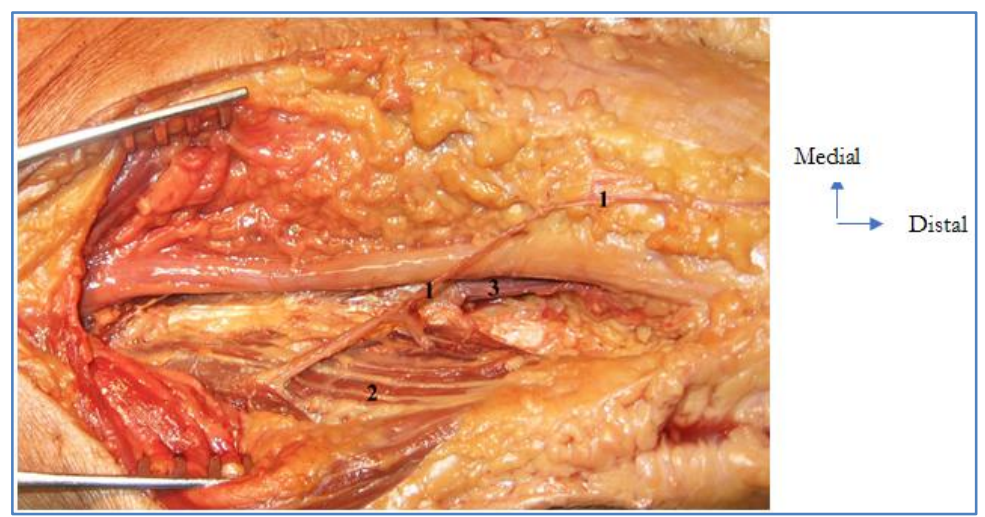

Fig-10: Left popliteal fossa, perforation of the biceps muscle 1- small saphenous vein; 2- femoral biceps muscle; 3- popliteal vein 


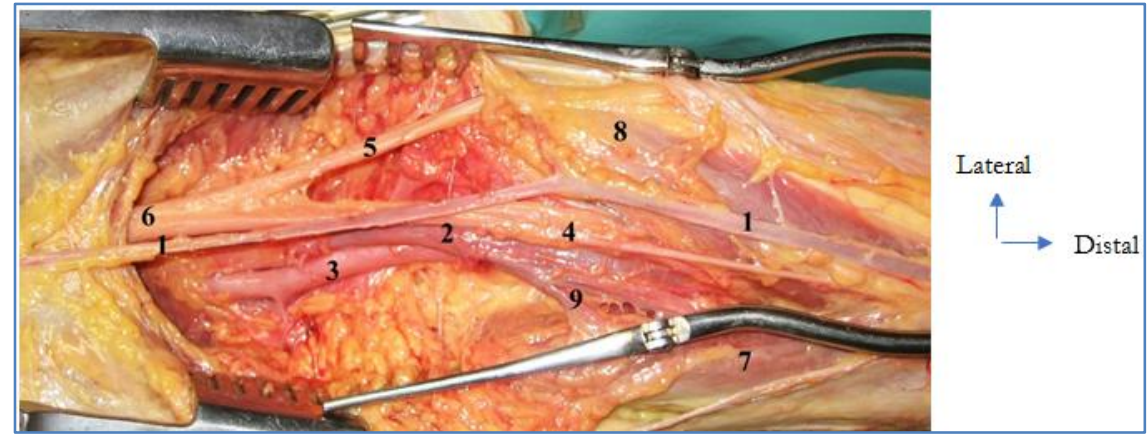

Fig-11: Right popliteal fossa, no arch and posterior femoral extension of the small saphenous vein

1- small saphenous vein; 2- popliteal vein; 3- popliteal artery; 4- tibial nerve; 5- peroneal nerve; 6- sciatic nerve; 7- internal twin muscle; 8- external twin muscle; 9-vein internal twin

Table-1: Morphological parameters

\begin{tabular}{|l|l|l|}
\hline Paramètres morphologiques & Nombre & Pourcentage \% \\
\hline 1 vein & 60 & 96,8 \\
\hline 2 veins & 2 & 3,2 \\
\hline Presence sapheno-popliteal junction & 28 & 45 \\
\hline Absence sapheno-popliteal junction & 34 & 55 \\
\hline
\end{tabular}

\section{DISCUSSION}

The variability of termination of the small saphenous vein is a result of the complexity of its embryologenesis. The classic ending in the form of a arch in the popliteal vein, is found in only about $60 \%$ of cases. In $30 \%$ of cases, it is done in the thigh, either in the great saphenous vein, or in the muscle veins, or even in the femoral vein. In $10 \%$ of cases, the small saphenous vein ends at the level of the calf in the muscular veins [6]. Gillot [7] classifies them in:

- A low level end: the sapheno-popliteal junction is at most 5-6 $\mathrm{cm}$ from the femoral condyles;

- An middle level termination: often shifted to the neighboring muscles (half-membranous, femoral biceps) to join the deep femoral vein or the superficial femoral vein;

- A high level end: at the fémoro-popliteal confines, the SSV reachs the third perforator and deep femoral vein or ends in the popliteal vein to merge flush with the adductor ring.

The typical ending with an arch thrown into the popliteal vein (Mercier type 1) is the most common. We found it in $45 \%$ of the cases. Mercier [2] finds this modality in $80 \%$ of cases. On the other hand, Kim [8] finds that arch termination is much more common with $95.8 \%$ in his series of 120 cases. In the same way, Uhl [9] describes arch termination in $89 \%$ of the normal population. Kosinski [1] reports the existence of arch in $57.8 \%$ of his cases. Schweighofer [10] individualizes $75.58 \%$ of sapheno-popliteal junctions in a dissection series of 86 small saphenous veins. Indeed, except the Kosinski study [1], the termination rate of SSV in the popliteal vein found, in the literature, is significantly higher than in our series. This result is probably related to the fact that the authors consider the termination of afferent branches SSV in the popliteal vein so we consider ourselves the end of the SSV trunk. In our series, the SSV arch was sometimes anastomosed to a superficial vein of the thigh (posterior cutaneous vein of the thigh), which Kosinski [1] observed on half of the SSV arch.

Anastomosis with the muscular afferent veins, especially the twin veins, has attracted the attention of several authors. The study of the interferences between the deep and superficial circulation at the sural level, is at the origin of the muscular venous insufficiency [26]. Kim [8] notes a common core of the SSV arch with a twin vein in $13 \%$ of cases the trunk of the internal twin veins gets into the concavity of the arch in $31.1 \%$ of cases. The misrecognition of this type of termination and its poor take in are responsible for re-interventions for recurrence of popliteal varicose veins following SSV stripping [3]. Resection of the SSV arch immediately in contact with the popliteal vein is the universally adopted surgical method. It would be preferable to perform a crossectomy with SSV arch's afferent branches ligation (incompetent, perforating twin veins) to eliminate any causes of reflux by the afferent network. Isolated crossectomy is insufficient when the trunk is fed against the current by incompetent twin veins. In this case, it is necessary to prefer the stripping [12].

The double termination in the popliteal vein and in the great saphenous vein that we observed in only one case is not uncommon. It corresponds to type 2 of Mercier. Kosinski [1] brings in $15.3 \%$ and Balasubramaniam [13] in 53\% of his series.

The terminal duplication of SSV arch observed in 3 of our dissections is reported by Kim [8] in $1.6 \%$ of cases. Lack of knowledge about terminal duplication can be a source of recurrence. It requires a doublé crossectomy associated or not with a stripping [14]. 
The SSV arch is most often done on the popliteal vein in the popliteal fossa. The topographical variations of the SSV arch are very important. This should be located normally on the middle part of the popliteal fossae or slightly off the vertical axis and about the height or slightly above the horizontal axis. Very often, the SSV arch is located further out ( 0.5 to $1.5 \mathrm{~cm})$, quite unusually a little more inside. The SSV arch is often located higher (at 1,2,3 cm and up to 4 $\mathrm{cm}$ ). In addition, the SSV arch can be both higher and further out. The opposite is very rare [15]. This ending can be high, normal or low depending on the authors. Balasubramaniam [13], taking as a reference the lower edge of the lateral femoral condyle, found $23.3 \%$ of low level (below the condyle), $6.7 \%$ of high level (more than $100 \mathrm{~mm}$ above the condyle) and $70 \%$ of normal endings (between the 2). With this same marker, Kim [8] located the sapheno-popliteal junction at $44.7 \mathrm{~mm}$ of the femoral condyle, opposite the popliteal fold, that he proposes as approach of the SSV arch. Compared to the articular line of the knee, O'Donnell [16] also describes a normal termination at $5 \mathrm{~cm}$ above the line spacing; a high termination, above the line spacing ( $1 / 3$ of the cases) and low termination, below the line spacing (5$10 \%)$.

O'Donnell [16] places the sapheno-popliteal junction about $5 \mathrm{~cm}$ above the joint space in approximately $75 \%$ of cases. Perrin [17], is between 2 and $15 \mathrm{~cm}$ above the knee joint space in $50 \%$ of cases and Kosinski [1] 4 to $5 \mathrm{~cm}$ above the line spacing. This configuration is not the case for Uhl [9] which finds $30 \%$ of low endings and maintains that at this level the small saphenous vein often has a common venous trunk with the twin veins. For Aloïso [18], the level of SSV involvement in the popliteal vein varies from $9 \mathrm{~cm}$ above the head of the fibula to mid-calf.

From our study, in addition to the joint line of the knee which is the classic reference, we propose a second repere which is subcutaneous and easily identifiable: the head of the fibula. Thus, this should make it possible to bring more precision to the identification and to avoid the approaches without success and unsuccessful surgical methods.

In relation to these 2 reperes, the saphenopopliteal junction is located on average $4.20 \mathrm{~cm}$ above the knee joint line and $4.22 \mathrm{~cm}$ inside the vertical line passing through the head of the fibula.

The existence or not of a small saphenous vein arch is itself a problem of clinical evaluation and surgical approaches in the course of the SSV insufficiency. To this problem is added the difficulty that the surgeon may encounter for repere the SSV arch. The aforementioned results make a good clinical examination of the veins of the lower limb essential, but especially the carrying out of a preoperative mapping before any small saphenous vein approach.
In addition, the termination of the small saphenous vein can be done without an arch and outside the popliteal vein. Kim [8] found $4.2 \%$ of terminations above the popliteal fossa including two endings in the femoral vein, two terminations in the great saphenous vein and a termination in the deep femoral vein.

Scwheighofer [10] describes $24.42 \%$ of small saphenous veins that continue their course to the thigh without specifying the termination.

In our series, the SSV joins the upper part of the great saphenous vein (GSV) in 9 cases: either exclusively or it divides into 2 branches that join one the GSV and the other in the posterior muscular lodge of the thigh. Kosinski [1] observed the first situation in $12.9 \%$ of cases and the second situation in $6.4 \%$ of cases and confirms the existence, at this level, an anastomose between SSV and small popliteal veins, on the one hand, and with the muscular veins, on the other hand.

The termination of the SSV in the muscles of the thigh as perforating corresponds to the type 6 of Mercier. Indeed, through the perforating veins, the SSV joins the deep femoral vein in $25.80 \%$ of cases. This type of termination is reported by Kosinski [1] in $18.6 \%$ of cases, it confirms the existence of cutaneous and muscular anastomoses. This pathway to the thigh is subfascial and subcutaneous in $9.67 \%$, joining the posterior vein of the thigh and the superficial femoral vein (Mercier type 5). This situation explains the isolated varicoses on the posterior side of the thight that will be incitate to explore the deep network venous of the lower limbs.

The small saphenous vein joins the twin veins in $3.22 \%$ of cases. This type of termination is reported Kosinski [1] en $1.6 \%$ of the cases, it is related type 6 Mercier.

The presence of SSV reflux is a significant factor in the recurrence of venous ulcers in patients with severe chronic venous insufficiency $[16,19]$. The localization and the termination variations of the sapheno-popliteal junction are responsible for the high rate of recurrent saphenous-popliteal venous insufficiency that reaches $30 \%$ versus $7 \%$ for the sapheno-femoral junction [13]. Indeed, Perrin [20] imputes $21.9 \%$ of varicoses recurrence after SSV surgical treatment.

The arch termination is most common in patients with lower extremity varices because it is often responsible for pathological reflux [9].

Anatomic variations are sources of incomplete surgical procedures or recurrences that are explained by the lackof knowledge of perforators or untreated pathological anastomoses [21]. The main sources of 
postoperative varicoses vein recurrence in the popliteal fossa are the unrecognized terminal duplication, not ligated at the right place (persistent SSV stump), the common involvement of the small saphenous and saphenous veins in the popliteal vein, the presence of a vein in the popliteal fossa, an incompetent perforator, a bulky incompetent twin vein. One must have these situations in mind and prefer stripping to the ligature that is a source of postoperative recurrence [14, 22].

SSV or reflux surgery in the popliteal fossa in SSV insufficiency is easier and more effective when anatomic (topographic and morphological) accuracies are obtained in addition to physiopathological data [12]. These precisions are imperative for the surgery of recurrences [22]. When ultrasound or duplex scanner do not provide satisfactory information on variations or when the popliteal fossa is highly altered, table varicography is necessary. In particular, when the SSV rises higher into the femoral veins or the great saphenous vein $[21,23,24]$. This precaution reduces recurrences [25]. In sclerosis, the SSV arch should be retrieved over an area $5 \mathrm{~cm}$ wide and $5 \mathrm{~cm}$ below the popliteal fold due to the large variability [26]. Surgically, several strategies are opposed.

The use of RFA, EVLA and sclerotherapy in the treatment of venous insufficiency of the small saphenous vein is done by taking into account the different methods of termination and distribution for a long-term occlusion of the target vein [27].

\section{CONCLUSION}

The existence of an arch as the end of the small saphenous vein in the popliteal fossa is not the rule. This vein has several termination modalities that must be taken into account in all venous diagnostic and therapeutic procedures. Pre-and intra-operative Doppler ultrasonography should be established as a rule for the efficiency of open and endovenous surgical techniques of the small saphenous vein.

\section{Authorization of the ethics comittee}

The Ethics Committee of the Faculty of Medicine and Odontotology of Dakar gave us its agreement for the realization of this study.

\section{Conflicts of interest}

The authors of this article declare that there is no conflict of interests.

\section{REFERENCES}

1. Kosinski, C. (1926). Observations on the superficial venous system of the lower extremity. Journal of anatomy, 60(Pt 2), 131.

2. Mercier, R. (1973). Quelques points d'anatomie de la veine saphéne externe. Phlébologie, 26(2), 191196.

3. Creton, D. (1999). 125 reinterventions for recurrent popliteal varicose veins after excision of the short saphenous vein. Anatomical and physiological hypotheses of the mechanism of recurrence. Journal des maladies vasculaires, 24(1), 30-36.

4. Boersma, D., Kornmann, V. N., Van Eekeren, R. R., Tromp, E., Ünlü, Ç., Reijnen, M. M., \& de Vries, J. P. P. (2016). Treatment modalities for small saphenous vein insufficiency: systematic review and meta-analysis. Journal of Endovascular Therapy, 23(1), 199-211.

5. Atasoy, M. M., Gümüş, B., Caymaz, İ., \& Oğuzkurt, L. (2014). Targeted endovenous treatment of Giacomini vein insufficiencyassociated varicose disease: considering the reflux patterns. Diagnostic and Interventional Radiology, 20(6), 481.

6. Elbaz, C.(1985). La chirurgie de la saphène externe. Phlébologie, 38(3) :475-483.

7. Gillot, C. (1999). Les veines superficielles du membre inférieur. Morphologie, 83(260), 19-28.

8. Kim, S. Y., Park, E. A., Shin, Y. C., Min, S. I., Lee, W., Ha, J., ... \& Min, S. K. (2012). Preoperative determination of anatomic variations of the small saphenous vein for varicose vein surgery by three-dimensional computed tomography venography. Phlebology, 27(5), 235 241.

9. Uhl, J. F., \& Gillot, C. (2007). Embryology and three-dimensional anatomy of the superficial venous system of the lower limbs. Phlebology, 22(5), 194-206.

10. Schweighofer, G., Mühlberger, D., \& Brenner, E. (2010). The anatomy of the small saphenous vein: fascial and neural relations, saphenofemoral junction, and valves. Journal of vascular surgery, 51(4), 982-989.

11. Van Der Stricht, J. (1993). La saphène externe, son passé, son avenir. Phlébologie, 46(4), 539-549.

12. Perrin, M. (1995). Chirurgie de l'insuffisance veineuse superficielle. Encycl Méd Chir (ParisFrance), Techniques Chirurgicales. Chirurgie Vasculaire, 1995, 43-161.

13. Balasubramaniam, R., Rai, R., Berridge, D. C., Scott, D. J. A., \& Soames, R. W. (2009). The relationship between the saphenopopliteal junction and the common peroneal nerve: a cada-veric study.

14. Rettori, R. (1998). Récidives variqueuses postopératoires au niveau du creux poplité: Données anatomiques guidant l'exploration ultrasonographique et corollaires chirurgicaux. Journal des maladies vasculaires, 23(1), 54-60.

15. Tournay, R. (1973). Varicose de la saphène externe. Difficultés des traitements, incidents, accidents, résultats des différentes méthodes de traitement. Plébologie, 26:131-132.

16. O'Donnell Jr, T. F., \& Iafrati, M. D. (2007). The small saphenous vein and other'neglected'veins of 
the popliteal fossa: a review. Phlebology, 22(4), 148-155

17. Perrin, M. (1994). Insuffisance veineuse chronique des membres inferieurs. Generalites. Rappel anatomique et physiologique. Encycl Med Chir (Paris-France) Techniques Chirurgicales. Chirurgie Vasculaire, 43-160.

18. Aloïso, R.(1968). Variations anatomiques et gadgets chirurgicaux au cours de la chirurgie des varices des membres inférieurs. Concours Med, 90(52): 9049-9055.

19. Lin, J. C., Iafrati, M. D., O'Donnell Jr, T. F., Estes, J. M., \& Mackey, W. C. (2004). Correlation of duplex ultrasound scanning-derived valve closure time and clinical classification in patients with small saphenous vein reflux: is lesser saphenous vein truly lesser?.Journal of vascular surgery, 39(5), 1053-1058.

20. Perrin, M., Lepretre, M., \& Becker, F. (1980). Role of the external saphenous vein in repeat surgery of primary varicose veins of the lower limbs. Phlebologie, 33(2), 321-327.

21. Payen, B. (1985). Rappel anatomique de la veine saphène externe. Phlébologie, 38(3), 453-461.
22. Staelens, I. (1993). Complications des reprises dans la fosse poplité: Complications de la chirurgie veineuse superficielle des membres inférieurs. Phlébologie, 46(4), 597-599.

23. Lagadec, B.(1987). Opacification per-opératoire de la portion terminale de la petite veine saphène. Phlébologie, 40(2):399-407.

24. Perrin, M., Bolot, J. E., GENEVOIS, A., \& HILTBAND, B. (1988). La phlébographie poplitée dynamique. Phlébologie, 41(2), 429-440.

25. Hobbs, J. T. (1993). Lésions de la veine poplitée et autres complications de la chirurgie veineuse superficielle dans les récidives de la fosse poplitée: Complications de la chirurgie veineuse superficielle des membres inférieurs. Phlébologie, 46(4), 591-595.

26. Van, Der., Molen, H.R., Mertens, A.M.(1980). Quelques remarques statistiques, cliniques et thérapeutiques au sujet de la saphène externe. Phlébologie, 33(2):301-306.

27. Doeke, B., Verena, N., Kornmann, N. (2015). Treatment Modalities for Small Saphenous Vein Insufficiency: Systematic Review and Metaanalysis. Journal of Endovascular Therapy, 1-13. 